\title{
Motor assessment in patients with Duchenne muscular dystrophy
}

\author{
Avaliação motora em pacientes com distrofia muscular de Duchenne \\ Gabriela Palhares Campolina Diniz', Laura Maria de Lima Belizário Facury Lasmar², Juliana Gurgel Giannetti³
}

\begin{abstract}
Objective: Evaluate muscle force and motor function in patients with Duchenne muscular dystrophy (DMD) in a period of six months. Method: Twenty children and adolescents with diagnosis of DMD were evaluated trough: measurement of the strength of the flexors and extensors of the shoulder, elbow, wrist, knee and ankle through the Medical Research Council (MRC), and application of the Motor Function Measure (MFM). The patients were evaluated twice within a six-month interval. Results: Loss of muscle strength was identified in the MRC score for upper proximal members $(t=-2.17, p=0.04)$. In the MFM, it was noted significant loss in the dimension $1(t=-3.06, p=0.006)$. Moderate and strong correlations were found between the scores for muscular strength and the MFM dimensions. Conclusion: The MFM scale was a useful instrument in the follow up of patients with DMD. Moreover, it is a more comprehensive scale to assess patients and very good for conducting trials to evaluate treatment.
\end{abstract}

Key words: Duchenne muscular dystrophy, motor function measure, medical research council.

\section{RESUMO}

Objetivo: Avaliar a força muscular e função motora em pacientes com distrofia muscular de Duchenne (DMD) em intervalo de seis meses. Método: Vinte crianças e adolescentes com diagnóstico de DMD foram avaliados quanto às seguintes medidas: força de flexores e extensores de ombro, cotovelo, punho, quadril, joelho e tornozelo, por meio do Medical Research Council (MRC) e aplicação da Medida da Função Motora (MFM). Os pacientes foram analisados em dois momentos, com intervalo de seis meses. Resultados: Observou-se perda de força muscular identificada por meio da MRC para membros superiores proximais ( $t=-2,17, p=0,04)$. Na MFM, observou-se perda significativa na dimensão 1 ( $t=-3,06, p=0,006)$. Foram registradas correlações médias a fortes entre os escores de força muscular e as dimensões da MFM. Conclusão: A escala MFM mostrou ser um instrumento útil no acompanhamento dos pacientes com DMD. É uma escala funcional, o que a torna boa candidata para o acompanhamento de pacientes com DMD em uso de novas drogas.

Palavras-Chave: distrofia muscular de Duchenne, medida da função motora, medical research council.

Neuromuscular diseases (NMD) are genetic or acquired entities whose primary lesion may be in the anterior horn of the spinal cord, peripheral nerves, neuromuscular junction or in the muscle ${ }^{1}$. The NMDs worldwide prevalence estimate, together, is 1:3500 individuals ${ }^{2}$. In childhood, the most frequent NMD is Duchenne muscular dystrophy (DMD), a recessive $\mathrm{X}$-linked inherited disorder with worldwide incidence around 1 in 4.000 newborn boys. The onset of the disease frequently occurs before the age of five years. The first symptoms are walking problems due to symmetrical weakness of the lower limbs muscles, often associated to calf pseudohypertrophy. There is a slowly weakness progression over time with involvement of the upper limbs and respiratory muscles ${ }^{3}$.
The search for an evaluation method that may quantify the NMDs and DMD patients muscular strength has been frequent in the literature. Several methods of analysis and monitoring of NMDs patients have been proposed, and some protocols have been established from the 1980 's $\mathrm{s}^{4-10}$.

Some scales have been developed for evaluation of specific NMDs including the Hammersmith Motor Ability Score (HMAS), used for spinal muscular atrophy (SMA) and $\mathrm{DMD}^{10,11}$, the Brooke score for $\mathrm{DMD}^{4}$, the Vignos score ${ }^{12}$ and the Egen Klassification (EK) scale for DMD and SMA ${ }^{13}$. The need for special training to use them is a problem for their use in the everyday clinical practice, restricting their use for research purposes.

\footnotetext{
${ }^{1}$ Fisioterapeuta do Ambulatório de Doenças Neuromusculares do Hospital das Clínicas da Universidade Federal de Minas Gerais (UFMG). Mestre em Ciências da Saúde pela UFMG, Minas Gerais MG, Brasil;

${ }^{2}$ Professora adjunta, Doutora do Departamento de Pediatria da UFMG, Minas Gerais MG, Brazil;

${ }^{3}$ Professora adjunta, Pós-doutorada, do Departamento de Pediatria da UFMG, Minas Gerais MG, Brazil.

Correspondence: Gabriela Palhares Campolina Diniz; Rua Dr. Juvenal dos Santos 337 / 101; 30380-530 Belo Horizonte MG - Brasil;

E-mail:gabrielapcd@gmail.com

Conflict of interest: There is no conflict of interest to declare.

Received 10 June 2011; Received in final form 13 December 2011; Accepted 22 December 2011
} 
The motor function measure (MFM) scale was developed by a group of French researchers in 2005. This technique allows the evaluation of patients presenting different NMD with six years old or more. The scale is designed to assess motor function and progression of weakness in a variety of neuromuscular disorders. It is applicable to both ambulant and non ambulant patients with a range of severity. The validation included 303 patients with 6-62 years, with different $\mathrm{NMD}^{14}$. The scale is subdivided into three dimensions: dimension 1 (D1) studies the standing position and transfers (13 items); dimension 2 (D2) investigates the axial and proximal limb motor function (12 items); and dimension 3 (D3) evaluates distal limb motor function (7 items). Each item is given a point from zero to three and the values are added in a percentage for each dimension and a scale total percentage value obtained.

In 2008, the MFM was validated for Portuguese language by a Brazilian physiotherapist, that showed minimal variability and high reliability in its aplication ${ }^{15,16}$. An adaptation of the MFM is under validation for NMD children under seven years ${ }^{17}$. In 2009, Vuillerot et al., performed a follow-up study using the MFM scale in DMD patients. There were two patient's groups - one was composed by DMD patients taking steroids regularly and the other by DMD patients without taking steroids. The patients were evaluated at three months and one year of follow up. At the end of the study, the authors concluded that the patients using steroids showed a more stable course. They also pointed the importance of the six months evaluation which was not performed in that study ${ }^{18}$.

The current study aimed to investigate the strength and the motor function of DMD at the starting and final moment, with a six months interval, using the Medical Research Council (MRC) and the MFM and to correlate the MFM and MRC.

\section{METHODS}

A prospective study including 20 patients with DMD was carried out and monitored in the NMD Clinics of the Hospital das Clínicas, Universidade Federal de Minas Gerais (UFMG) in the period between July 2008 and May 2009.

It included children and adolescents aged from 6 to 19 years, diagnosed with DMD, confirmed by DNA analysis or muscular biopsy with histochemical and immunohistochemical study.

Children and adolescents who had no cognitive ability to understand verbal commands or who refused to participate were excluded.

A standardized protocol was developed and applied by the same examiner twice within a six-month interval. Two scales were used, the $\mathrm{MRC}^{10,19}$ and the $\mathrm{MFM}^{14-16}$.

According to the MRC, the muscle strength of muscular groups was evaluated including: flexors and extensors from shoulder, elbow, wrist, hip, knee and ankle. A score system was used for the muscular strength analysis giving it point values between zero to five. Thus, zero = no contraction; one point $=$ flicker or trace of contraction; two points = active a movement, with gravity eliminated; three points = active movement against gravity; four points = active movement against gravity and resistance; five points $=$ normal power ${ }^{9}$. In all the strength tests the measure was achieved from both left and right sides to minimize the handedness influences, as well as to exclude the asymmetrical involvement of the muscle groups.

The muscular strength scores were calculated using the formula ${ }^{10}$ :

\section{$\% M R C=$ Sum of the scores $X 100$ Number of tested muscles $X 5$}

Based on this formula, different scores were obtained: the proximal upper limb (shoulder and elbow), distal upper limb (wrist), proximal lower limbs (hip and knee) and distal lower limb (ankle) strength.

All the patients were evaluated by the same physiotherapist, always in the same period in the afternoon, between 1:30 p.m. and 4:30 p.m. Two evaluations were carried out with a six month interval. The tests were applied always in the same order: MFM, MRC. The findings in each scale, at the start and final moments, were compared.

The material used for the application of the MFM scale was as follows: a mattress, a table, a chair, a tennis ball, a pencil, A4 paper sheets, a CD, ten coins of ten cents and a stopwatch.

\section{STATISTICAL ANALYSIS}

The sample was non-randomized and, according to the inclusion criteria, 20 DMD patients were selected.

The paired $t$-tests and the Mann-Whitney were used, respectively, for comparison between means and medians.

Also, we evaluated the correlation between the muscular strength scores and the MFM scale dimension as follows: each muscular strength score was correlated with each of the three dimensions of the MFM scale. The correlation was carried out by the Spearman correlation test ${ }^{20}$. It was also used the simple linear regression whose variable-answers were the MFM scale dimensions; and the predictor variables were the muscular strength scores. These correlations were carried out in the two stages: the initial and final.

The level of statistical significance was $\mathrm{p}<0.05$.

The study protocol and the terms of consent were approved by the UFMG Ethics and Research Committee. All participants and their parents provided their informed consent to participate. 


\section{RESULTS}

Among the 20 DMD patients, 12 (60\%) had already lost the ambulation when the first evaluation was performed. The median age of ambulation lost was nine years.

To perform the MFM application we spent 22.9 minutes at the first evaluation and 18.9 minutes at the final evaluation.

The results of the differences between means and/or medians between the scores of muscular strength of upper and lower limbs at the start and at the final moments using the MRC in DMD patients is showed in Table 1. There were statistically significant losses in the score of the proximal muscular strength of upper limbs in the six month interval.

The scores of the MFM scale, at the start and final moments, are showed in Table 2. There was difference statistically significant among the mean scores only in the D1 of MFM scale in a six month period.

The scores of D3 of the MFM in the non-ambulatory DMD patients are demonstrated in Table 4. The non-ambulatory DMD patients had lost upper limb function in a period of six months, demonstrated by the dimension 3 of the MFM ( $\mathrm{p}=0.04)$.

The correlations between the MFM scale dimensions and the MRC in DMD patients are showed in Table 4. The

Table 1. Analysis of muscle strength of upper and lower limbs at the start and final moments, according to Medical Research Council scale $(n=20)$.

\begin{tabular}{lcccc} 
Item & Average $\pm S D$ & $\begin{array}{c}\text { Median } \\
\text { (Range) }\end{array}$ & $\mathrm{t}$ & $\mathrm{p}$-value \\
\hline Score MSPUL start & $25.4 \pm 5.9$ & $26(12-34)$ & & \\
Score MSPUL final & $23.6 \pm 4.9$ & $24(16-31)$ & -2.17 & 0.04 \\
Score MSDUL start & $15.9 \pm 3.2$ & $16(8-20)$ & & \\
Score MSDUL final & $15.9 \pm 2.2$ & $16(12-20)$ & 0.39 & 0.7 \\
Score MSPLL start & $19.2 \pm 8.7$ & $20.5(4-31)$ & & \\
Score MSPLL final & $17.2 \pm 7.8$ & $15(4-31)$ & -1.96 & 0.06 \\
Score MSDLL start & $11.0 \pm 5.2$ & $12.5(0-18)$ & & \\
Score MSDLL final & $9.5 \pm 5.2$ & $9(2-18)$ & -1.3 & 0.2 \\
\hline
\end{tabular}

SD: standard deviation; MSPUL: muscle strength of proximal upper limb; MSDUL: muscle strength of distal upper limb; MSPLL: muscular strength of proximal lower limb; MSDLL: muscular strength of distal lower limbs.

Table 2. Scoring distribution of patients according to scale motor function measure at the start and final moments, as a percentage $(n=20)$.

\begin{tabular}{lcccc} 
Item & Average $\pm S D$ & Median (Range) & $t$ & $p$-value \\
\hline D1Total start & $28.95 \pm 30.4$ & $9.0(0-77)$ & & \\
D1Total final* & $22.55 \pm 26.4$ & $8.0(0-74)$ & -3.06 & 0.006 \\
D2Total start & $82.30 \pm 16.7$ & $89.0(39-97)$ & & \\
D2Total final* & $82.95 \pm 17.2$ & $87.5(50-100)$ & -0.11 & 0.916 \\
D3Total start & $87.65 \pm 12.5$ & $90.0(52-100)$ & & \\
D3Total final* & $85.65 \pm 14.6$ & $90.0(43-100)$ & -1.09 & 0.290 \\
D Total start & $61.70 \pm 18.1$ & $57.0(29-89)$ & & \\
D Total final* & $58.6 \pm 18.3$ & $55.5(29-88)$ & -2.17 & 0.043 \\
\hline
\end{tabular}

*A patient excluded. D: dimension; SD: standard deviation. muscular strength scores presented moderate to strong correlations with the MFM scale dimensions, both at the initial and the final moments.

The correlation between the dimension 1 of the MFM and the muscular strength score of proximal lower limbs at the final moment in DMD patients is demonstrated in Fig 1. It is noted that $77.1 \%$ of the variation of the $\mathrm{D} 1$ of the MFM are explained by the proximal lower limbs muscular strength score.

The correlation between the dimension 2 of the MFM and the muscular strength score of proximal upper limbs at the final moment in DMD patients is showed in Fig 2. It is noted that almost $77 \%$ of the variation of $\mathrm{D} 2$ of the MFM are explained by the proximal upper limb muscular strength score.

Table 3. Comparation of dimension 3 of the motor function measure in the start and final moments in non-ambulatory patients with Duchenne muscular dystrophy.

\begin{tabular}{lccc} 
Item & $\mathrm{n}$ & Average \pm SD & \\
\hline D3 Total start & 12 & $84.8 \pm 14.5$ & \\
D3 Total final & 12 & $79.3 \pm 15.2$ & $\mathrm{p}=0.04$ \\
\hline
\end{tabular}

D: dimension; SD: standard deviation.

Table 4. Correlation between muscle strength, according to MRC scale, and function, according to scale motor function measure at the start and the final moment $(n=20)^{*}$.

\begin{tabular}{lccc} 
Item & D1 & D2 & D3 \\
\hline Score MSUL proximal 1 & $0,001(r=0.7)$ & $<0.001(r=0.8)$ & $<0.001(r=0.8)$ \\
Score MSUL distal1 & $0.001(r=0.7)$ & $<0.001(r=0.8)$ & $0.002(r=0.8)$ \\
Score MSLL proximal1 & $<0.001(r=0.9)$ & $0.001(r=0.7)$ & $0.002(r=0.6)$ \\
Score MSLL distal1 & $0.002(r=0.65)$ & $0.01(r=0.6)$ & $0.04(r=0.5)$ \\
Score MSUL proximal 2 & $<0.001(r=0.8)$ & $0.001(r=0.9)$ & $0.01(r=0.6)$ \\
Score MSUL distal2 & $0.06(r=0.4)$ & $<0.001(r=0.8)$ & $0.03(r=0.5)$ \\
Score MSLL proximal 2 & $<0.001(r=0.9)$ & $<0.001(r=0.8)$ & $0.02(r=0.5)$ \\
Score MSLL distal2 & $0.001(r=0.7)$ & $\star 0.001(r=0.8)$ & $0.01(r=0.6)$ \\
\hline
\end{tabular}

${ }^{*}$ One patient excluded at the end. MSUL: muscle strength of upper limb; MSLL: muscular strength of lower limb; 1: start moment; 2: final moment.

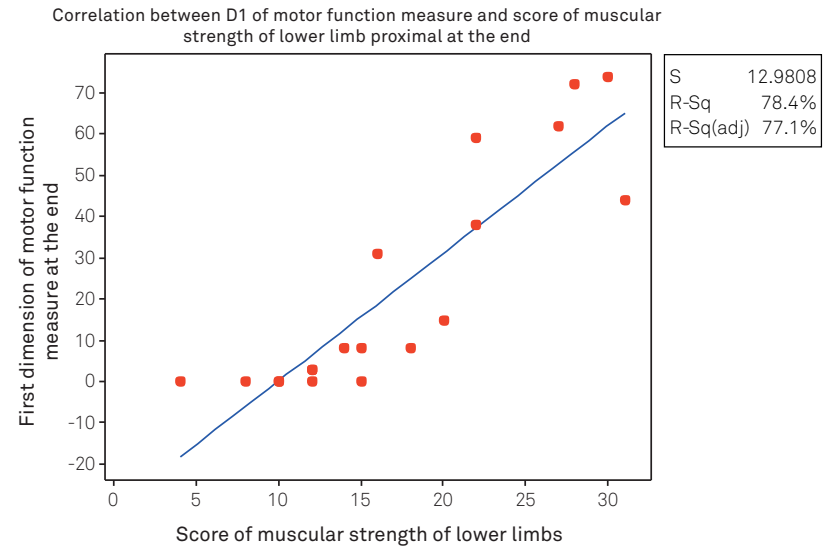

Fig 1. Correlation between dimension 1 of motor function measure and muscle score of proximal lower limbs at the final evaluation. 


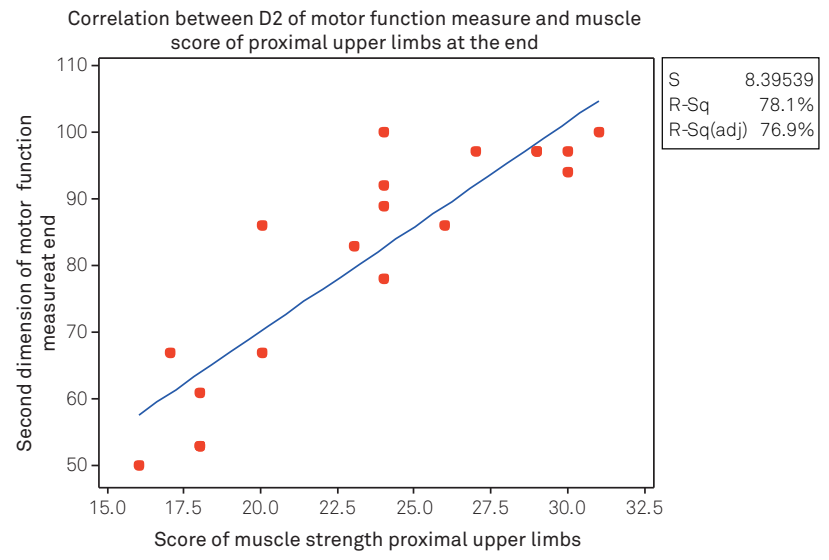

Fig 2. Correlation between dimension 2 of the motor function measure and muscle score of proximal upper limbs at the final evaluation.

\section{DISCUSSION}

One of the most significant findings in the DMD patient's neurological exam is the muscle weakness ${ }^{21}$. In addition, several NMD present worsening weakness and motor function along the years. Thus, the development of scales that allow the evaluation of patients with different forms of NMD, including DMD, has become a challenge. In this context, several studies were carried out and different scales were applied, and the MRC was originally one of the most used ${ }^{47}$. However, it is important to consider that the MRC measure the muscle strength exclusively. It does not asses the motor function, which nowadays is essential to improve the adaptation of NMD patients to daily activities and social life.

The present study used the MRC in the assessment of patient's muscle strength, nevertheless the evaluation was done analyzing specific muscular groups setting the proximal and distal muscular strength scores both for the lower and upper limbs. We found no significant difference in a six month interval between the initial and final evaluations of the proximal lower limbs strength, but statistically significant changes in the proximal muscular strength scores of upper limbs. The lack of changes in the two evaluations of the proximal lower limbs strength could be associated to the predominance of nonambulatory DMD patients (12 patients) in whose the muscle strength scores is low, frequently between 0 to $2-3$, with less variation over time. On the other hand, based in the natural history of the disease, in the non-ambulatory stage there is progressive weakness of upper limbs which is compatible with the statistically significant changes in the proximal muscular strength scores of upper limbs observed in the present study.

In this research, the MRC was associated to a functional scale. The chosen scale was the MFM, which was selected in view of some advantages: it can be used in ambulatory or non-ambulatory patients, evaluates the hand function and presents the subdivision into dimensions that can be independently assessed.
Similarly in 2007, Parreira et al. investigated the muscle strength and motor skills in $32 \mathrm{DMD}$ patients using corticosteroids. However, the authors used the MRC scale associated to others functional tests: the HMAS scale, the maximum weight lifting, time for walking nine meters and time for getting up off the floor. The conclusion was that it is possible to evaluate objectively and rapidly the DMD patients by the established measures. However, HMAS scale has limitations, including the lack of items to test hand functions, and in its original version presented several items that difficult the application in non-ambulatory patients.

The MFM was developed and validated in 2005 through a study that included 303 patients with different NMD, aged between 6-62 years old ${ }^{13}$. After one year, 152 of the 303 patients were reevaluated and there was significant reduction in the scale global score ${ }^{22}$. Since then, some studies are using this scale, pointing it as easy and useful scale for application in clinical practice and researches in NMDs.

Vuillerot, in 2009, investigated the motor function of DMD patients through the MFM scale in three different surveys: the first and the second one have monitored patients undergoing physiotherapy, for three months and one year, respectively. The third one compared patients treated with steroids and patients without any medication during a one year period. In three months interval, there was loss in the D1 and in one year there were losses in all the dimensions. However, the patients with steroids treatment had more stable values than the group with no treatment; and also in the D2 there were fewer losses. They also showed that a total score of 70\% of the MFM scale and a score of $40 \%$ of D1 are values that predict a loss of ambulation within one year in DMD patients. Notwithstanding, the authors underline the need for a study that evaluates the patients with a six month interval ${ }^{18}$.

In our study, we applied the MFM scale in DMD patients twice within a six-month interval. A statistically significant loss was noted in the D1. The dimension 1 evaluates standing position and transfers. It is important to consider that $60 \%$ (12 patients) of the DMD patients were non-ambulatory and, consequently, the items of the D1 could not be applied. So, the alteration observed in D1 was related to disease progression among the ambulatory patients, since the non-ambulatory DMD patients pointed zero and they were consequently excluded from D1 evaluation. The D2 evaluates axial and proximal motor function and D3 measures the distal motor function. In the present study, there were no changes in D2 and D3. However, when we analyzed the D3 results only in non-ambulatory DMD patients, we found a statistically significant change suggesting the progressive involvement of distal limb motor function in this stage of the disease. The MFM can be useful for the evaluation of disease progression even in a short period of time.

Concerning the analysis of upper limb function in DMD patients (with age ranging from 20 to 43 years), a recent 
study was performed by Bartels et al. ${ }^{23}$. They evaluated upper limb distal motor function using the D3 of MFM. The muscle strength and range of motion of upper limb were also assessed using the MRC, hand-held dynamometry and goniometry, respectively. The conclusion was that motor function was severely impaired and there is a wide variation in distal motor function, muscle strength and range of motion of the upper limbs. The muscle strength and range of motion explained $76 \%$ of the variance in upper limb distal motor function. The research suggests that preserving muscle strength and range of motion might be relevant for a better upper distal motor function in DMD adults ${ }^{23}$. However, they did not perform a follow up evaluation of the dimension 3 of MFM.

In the current study we performed analysis of the correlations between the MFM dimensions and MRC at the initial and final evaluations. There were few studies analyzing this correlation, but one article is highlighted since it made this analysis (correlation of MRC and MFM) in 100 adult patients (aged 18-78 years) with several NMD. The group included mostly patients with myotonic dystrophy (30\%) and fascio-scapular-humeral dystrophy (29\%). MFM, MRC were applied for lower and upper limbs face and trunk and the Brooke and Vignos score. The MFM was correlated to all the MRC scores, except for the face muscular strength score. The author's conclusion was that the MFM is useful in the evaluation of adult patients with myopaties, and they recommended the separated use of the three dimension scale ${ }^{24}$.

Similarly, ours results showed moderate to strong correlations between the MRC scores and the MFM scale dimensions at the initial and final evaluations. It means that the two scales are concordant allowing the use of the MFM scale as a choice scale in the follow-up of DMD patients, because it is more objective and allows the assessment of the motor function. Differently, the MRC is applicable exclusively for the muscle strength measure with a more restrictive clinical use.

Another relevant aspect of the MFM scale is related to the spending time for its application. In the original validation study of the scale, the spending time was in average 36 minutes. The literature also reports average time for MFM application from 30 to 40 minutes $^{14}$. In the current study, the averages were 22.9 minutes and 18.9 minutes in the initial and final evaluation, respectively.

Some factors, such as the professional training and the patient's level of understanding and collaboration, can intervene in the time of application of the MFM. Moreover, the inability to walk and stay in upright position leads to the impossibility of implementing some D1 items, which will be scored as zero, and consequently there will decrease the time of application. Considering that $60 \%$ of ours patients were nonambulatory, this fact could be directly related to the short time spent in the MFM application here.

This research presents some limitations, including the fact that trunk strength was not evaluated.

The current results indicate that MFM can be used to the assessment and for monitoring the follow up of DMD patients, even in a short interval of time, with reliable and reproducible results, as described in the literature ${ }^{18,22-24}$. As it is a method for clinical-functional assessment with good relation with the MRC, it is suggested that it can be very useful to check and follow up of DMD patients and treatment that may arise. Furthermore, it is emphasized that it is an easily applicable scale, requiring little time for the assessment (on average 20 minutes), well tolerated by patients and does not imply high financial expenditures.

In conclusion, the MRC scale showed changes in the scores of proximal upper limbs muscles strength in the interval of six months. Concerning the functional assessment by the MFM, it was noticed more impairment in the D1 score, and in nonambulatory patients there was lost in D3 of the MFM.

The moderate to strong correlations between the MRC and MFM scales show that they are concordant and suggest that the MFM scale can be useful in the follow-up of DMD patients.

It is noteworthy that instruments for the functional assessment of the patients, such as MFM, are more suitable for monitoring DMD patients by enabling the early detection of motor disorders, guiding the interventions needed to optimize the motor function and to improve the patients adaptation in their daily life activities. Furthermore, such instruments will also be useful to the assessment of the response to the different forms of treatment for the arising DMD.

\section{References}

1. MacDonald CM. Physical activity, health impairments, and disability in neuromuscular disease. Am J Phys Med Rehabil 2002; 81:S108-S120

2. Strehle EM. Long-term management of children with neuromuscular disorders. J Pediatr 2009;85:379-384.

3. Grange RW, Call JA. Recommendations to define exercise prescription for Duchenne muscular dystrophy. Exercise Sports Sci Rev 2007;35:12-17

4. Brooke MH, Griggs RC, Mendell JR, Fenichel GM, Shumate JB, Pellegrino RJ. Clinical trial in Duchenne dystrophy. I. The design of the protocol. Muscle Nerve 1981;4:186-197.

5. Florence JM, Pandya S, King WM, et al. Clinical trials in Duchenne dystrophy. Standardization and reliability of evaluation procedures. Phys Ther 1984;64:41-45.

6. Florence JM, Pandya S, King WM, et al. Intrarater reliability of manual muscle test (Medical Research Council Scale) grades in Duchenne's muscular dystrophy. Physical Therapy 1992;72:115-126.

7. Merlini L, Bertini E, Minetti C, et al. Motor function-muscle strength relationship in spinal muscular atrophy. Muscle Nerve 2004;29:548-552.

8. Pandya S, Florence JM, King WM, Robinson JD, Oxman M, Province MA. Reliability of goniometric measurements in patients with muscular dystrophy. Phys Ther 1985;65:1339-1342. 
9. Parreira SLS, Resende MBD, Peduto MDC, Marie SKN, Carvalho MS, Reed UC. Quantification of muscle strength and motor ability in patients with Duchenne muscular dystrophy on steroid therapy. Arq Neuropsiquiatr 2007;65:245-250.

10. Scott OM, Goddard C, Dubowitz V. Quantitation of muscle function in children: a prospective study in Duchenne muscular dystrophy. Muscle Nerve 1982;5:291-301.

11. Main M, Kairon H, Mercuri E, Muntoni F. The Hammersmith Functional Motor Scale for children with spinal muscular atrophy: a scale to test ability and monitor progress in children with limited ambulation. Eur J Padiatr Neurol 2003;7:155-159.

12. Vignos PJ, Spencer GE, Archibald KC. Management of progressive muscular dystrophy of childhood.JAMA 1963;184:89-96.

13. Steffensen B, Hyde S, Lyager S, Mattson E. Validity of the EK scale: a functional assessment of non-ambulatory individuals with Duchenne muscular dystrophy or spinal muscular atrophy. Physiother Res Int 2001;6:119-134.

14. Bérard C, Payan C, Hodgkinson I, Fermanian J. The MFM Collaborative Study Group. A motor function measure scale for neuromuscular diseases. Construction and validation study. Neuromuscul Disord 2005;15:463-470.

15. Iwabe C, Miranda-Pfeilsticker BH, Nucci A. Motor Function measure: portuguese version and reliability analysis. Rev Bras Fisioterap 2008;12:417-424.

16. Bérard C, Girardot F, Hodgkinson I, Payan C. e o grupo de estudo MFM. Medida da função motora para doenças neuromusculares. Manual do usuário, 2006. [ cited 2011 Sept 09]. Available at: http://www.mfmnmd.org/le-manuel-utilisateur.aspx

17. Bérard C, Vuillerot C, Girardot F,Hamroun D, Payan C.La Mesure de Fonction Motrice, une échelle validée por les MNM. [cited 2011 Sept 09]. Available at www.mfm-nmd.org/publications.aspx [

18. Vuillerot C, Girardot F, Payan C, et al. Monitorating changes and predicting loss of ambulation in Duchenne muscular dystrophy with the motor function measure. Dev Med Child Neurol 2009; 52:60-65.

19. Kendal FP, McCreary EK, Provance PG. Músculos, provas e funções. 4. ed. São Paulo: Manole ; 1995.

20. Pagano M, Gauvreau K. Correlação. Princípios de Bioestatística. 2a ed. São Paulo:Thomson; 2006:354-364.

21. Mutarelli EG. Propedêutica Neurológica: do sintoma ao diagnóstico. São Paulo: Editora Sarvier; 2000:23-58.

22. Bérard C, Payan C, Fermanian J, Girardot F, Groupe d'Etude MFM. La mesure de function motrice, outil d'evaluation Clinique des maladies neuromusculaires. Étude de validation. Rev Neurol 2006; 162:485-493.

23. Bartels B, Pangalila RF, Bergen MP, Cobben NAM, Stam HJ, Roebroeck ME. Upper limb function in adults with Duchenne muscular dystrophy. J Rehabil Med 2011;43:770-775.

24. Benaïm C, Sacconi S, Fournier-Mehouas M, Tanant V, Desnuelle C. Analyse de validité de la Mesure de la function motrice(MFM) en pratique de consulation adulte d' un centre de référence pour maladies neuromusculaires. Rev Neurol 2009;166:49-53. 